\title{
CYTOKINE-DEPENDENT INTERLEUKIN-8 EXPRESSION AND ITS ROLE IN CELL COMMUNICATION
}

\author{
STEVEN L. KUNKEL *THEODORE STANDIFORD, \\ AND *ROBERT M. STRIETER
}

\author{
DEPARTMENTS OF PATHOLOGY AND INTERNAL MEDICINE, \\ *Division of Pulmonary and Critical Care Medicine \\ UNIVERSITY OF MICHIGAN MEDICAL SCHOOL \\ ANN ARBOR, MICHIGAN
}

\section{INTRODUCTION}

The cascade of events that lead to the passage of immune cells from the vascular bed to a site of interstitial inflammation is extremely complex. For successful leukodiapedesis to occur, granulocytes must first physically adhere to endothelial cells that line post-capillary venules and then undergo directed migration in response to established chemotactic gradients. The transendothelial trafficking of these inflammatory cells occurs in the presence of altered blood vessel hemodynamics, vascular permeability changes and procoagulant activation. The importance of the chemotactic response is exemplified by the fact that normal elicitation still proceeds even during dramatic alterations in vessel hemostasis. The local environment may also contain a plethora of additional immune mediators, providing competition for these established chemotactic gradients. In this manuscript, we address various aspects of leukocyte elicitation and demonstrate the importance of proximal cytokines to a successful chemotactic response.

\section{THE GRANULOCYTE CHEMOTACTIC RESPONSE}

As demonstrated by electron microscopy in Figure $1 \mathrm{~A}$, a local inflammatory response may result in decreased blood flow and a state of leukoconcentration, favoring granulocyte-endothelial cell interactions. The actual binding phenomenon is mediated via the expression of a variety of adherence proteins found on both endothelial and inflammatory cells (Springer 1978). Although the mechanism(s) of adherence has clearly been shown to be mediated by specific receptor-ligand interactions, the passage of granulocytes through the endothelium-basement membrane barrier remains an enigma. This active process is shown in Figure $\mathrm{I} B$, where polymorphonuclear leukocytes have left the lumen of a vessel and are moving toward an inflammatory foci. It must be stressed that adherence 


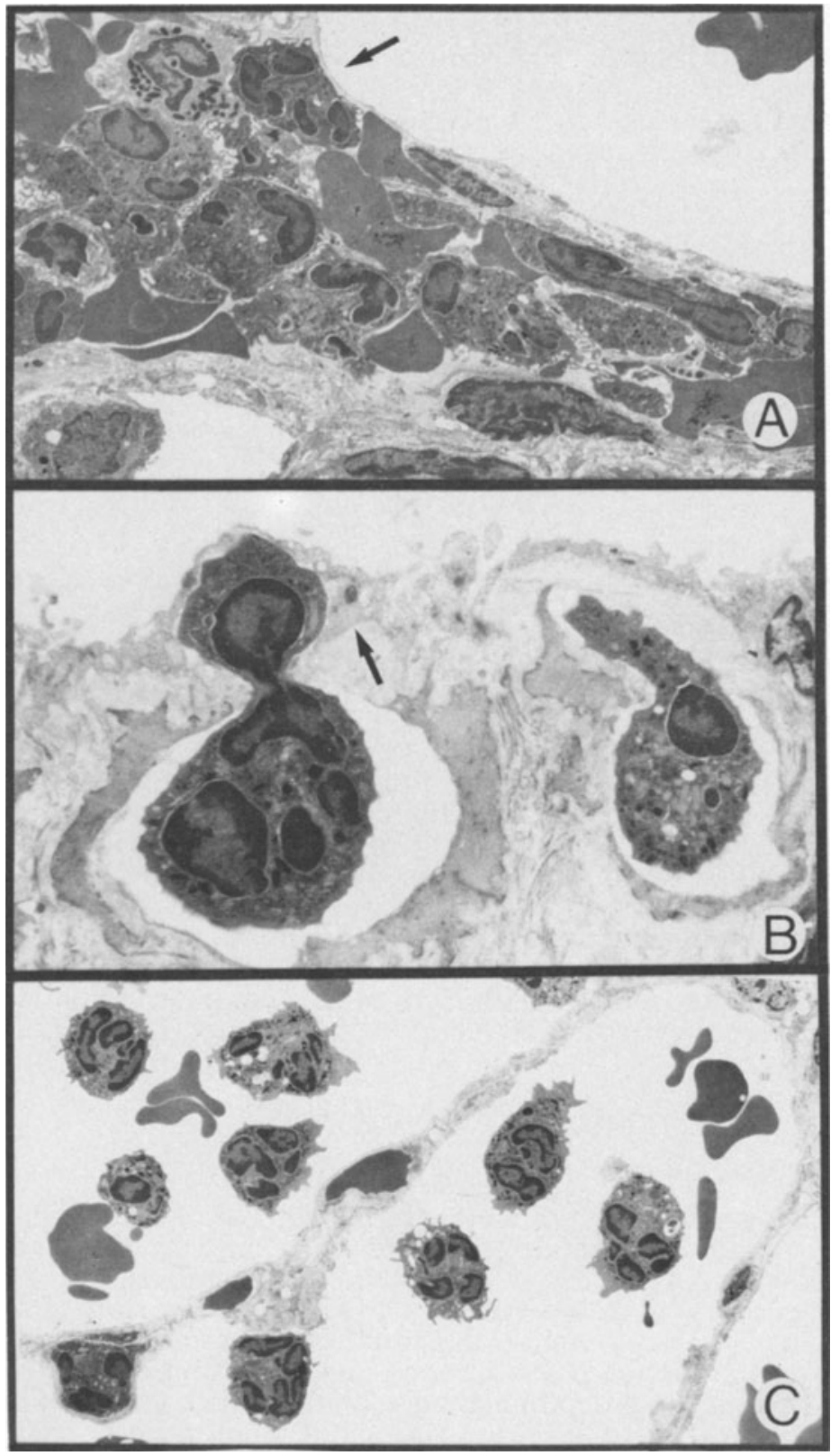

FIGURE 1. Electron micrographic assessment of granulocyte elicitation. 1A) Slowing of blood flow in an area of inflammation allows for leukoconcentration with subsequent adherence of neutrophils to the endothelium (arrow). 1B) The neutrophils can then move through the endothelium and basement membrane (arrow) and follow established gradients. 1C) The end result of trafficking is the collection of neutrophils at a site of inflammation to actively participate in the response (arrival of neutrophils to an inflamed alveolus). 
between granulocytes and endothelial cells is a very dynamic process, allowing for a reversible interaction between these cells. On the contrary, the migratory response to established gradients appears to be a major commitment for granulocytes. Once these cells pass the endothelium, digesting a small area of the subendothelial basement membrane, their normal migration through the interstitium to an inflammatory foci may be preset. The ability of granulocytes to strictly follow set chemical gradients is important, as this assures the timely arrival of these cells to participate in an inflammatory response. Although peripheral blood neutrophils are sentinel cells in the circulation, their ultimate role is determined by following chemotactic gradients to sites of tissue inflammation (Figure 1C).

A number of interesting and unexplained aspects still remain regarding the chemotactic response of immune cells. For example, the composition of the inflammatory cell infiltrate may be either static, and characteristic of an acute disease state, or dynamic and change as the immune response evolves. The latter situation implies that the stimuli and types of leukocytes involved in the initiation of inflammation may be quite distinct from those active in the maintenance and final resolution of the inflammatory reaction. This characteristic of inflammation is representative of the host's ability to generate specific signals to elicit individual populations of leukocytes at exact time intervals of the inflammatory response. Also, the recruitment of leukocytes to an inflammatory lesion may be mediated by a number of factors, including peptides (Schiffmann 1975), lipids (Hoover 1984), and proteins (Sauder 1984), demonstrating redundancy exists in the chemotactic response.

\section{INTERLEUKIN-8 AND GRANULOCYTE CHEMOTAXIS}

A variety of biologically active agents have proven to elicit an inflammatory cell chemotactic response when challenged in vivo. For example, the intradermal injection of lipopolysaccharide (LPS) can induce a brisk recruitment of granulocytes within hours (Issekutz 1987). This observation was significant, since LPS was shown not to be directly chemotactic for neutrophils (Sauder. 1984). Therefore, the in vivo effects of LPS are dependent upon the de novo production of chemotactic factors. Interleukin1 (IL-1) and tumor necrosis factor (TNF) were initially thought to be the LPSderived chemotaxins, as both of these cytokines can elicit a local in vivo infiltrate (Issekutz, 1987). Yet, neither highly purified preparation of IL-1 nor TNF are directly chemotactic for neutrophils. Confusion in this area has been partially clarified by the purification, cloning, and expression of a novel polypeptide with potent in vitro and in vivo granulocyte chemotactic/activating properties (Yoshimura 1987, Matsushima 1988, Lindley, 1988). Various investigators have labeled this protein: neutrophil activating factor (Thelen 1988), monocyte-derived neutrophil chemotactic factor (Yoshimura 1987), granulocyte chemotactic protein (Van Damme 1989), neutrophil chemotactic factor (Strieter 1989), and interleukin-8 (IL-8) (Van Damme 1989, Westwick, J 1989). Interleukin-8 is chemotactic for granulocytes at low nanomolar concentrations and can activate these cells via a calcium and protein kinase C dependent mechanism (Thelen 1988). 
Although IL-8 is a novel polypeptide and is structurally different from other chemotaxins (e.g. C5a) and cytokines (e.g. IL-1 and TNF), it does possess a high degree of nucleotide sequence homology with a super-gene family of inflammatory proteins (Table 1). These homologous proteins include: connective tissue-activating peptide III (Castor 1983), platelet factor-4 (Deuel; 1977), Beta-thromboglobulin (Begg 1978), v-src-inducible protein (Sugano 1987), a growth-related gene product labeled GRO/melanoma stimulating activity (MGSA) (Anisowicz 1987, Richmond 1988), a gammainterferon inducible cytokine named gamma IP-10 (Luster 1985), and a staphylococcal enterotoxin A-induced cDNA termed 3-10c (Schmid 1987). The latter investigation is especially noteworthy, since the nucleotide sequence of the 3-10c cDNA is in fact identical to the cDNA encoding IL-8. This seminal manuscript by Schmid and Weissmann (Schmid 1987) was instrumental in identifying the initial members of this super-gene family of iimmune mediators. The major structural similarity that identifies this family is the conservation of the relative positions of four cysteine residues (the first two cysteines being separated by one amino acid). These cysteine residues are extremely important, as they form disulfide bridges that are instrumental in forming the secondary structure and biologic activity of IL-8. The position of the cysteine residues in the IL-8 super-gene family is also important in distinguishing these proteins from an additional family of inflammatory polypeptides. This related super-gene family is comprised of a number of proteins, including human and murine JE (Rollins 1988), MIP-1 (Devatelis 1988), and human monocyte chemotactic protein (Yoshimura 1989).

Structural Homologues of Interleukin-8

Platelet Factor-4

Beta thromboglobulin

Platelet Basic Protein

GRO

MGSA $\mathrm{v}$-src-induced inducible protein

Gamma interferon-inducible IP-10

Connective Tissue Activating Protein

Staph Enterotoxin-A induced 3-10c

TABLE 1. Structural Homologues of Interleukin-8. Interleukin-8 belongs to a super gene family of related proteins that appear to be involved in either inflammation or growth. The position of four cysteins in the above polypeptides are conserved and disulfide bridges are a requirement for activity. 
As noted above, the elicitation of cells during the development of an inflammatory lesion may be in a constant state of change, suggesting that specific signals are generated to recruit a particular leukocyte population. This selectivity may have important implications with regard to the chemotactic activity of IL-8 for phagocytic cells. A number of laboratories have shown that IL-8 possesses selectivity for the recruitment of neutrophils, while monocytes are not responsive to IL-8 (Baggiolini 1989). Conversely, leukotriene $\mathrm{B}_{4}$, formylmethionylleucylphenylalanine, and $\mathrm{C} 5 \mathrm{a}$ are all potent chemoattractants for both peripheral blood monocytes and neutrophils. The selectivity of IL-8 may be of great importance, since the recruitment of primarily neutrophils to an acute inflammatory lesion is crucial for the normal development of the response.

\section{CYTOKINE NETWORKS INVOLVING INTERLEUKIN-8}

Our laboratory has been especially interested in the orchestration of acute, neutrophil mediated inflammation and the pathology associated with these disorders. While original studies identified peripheral blood monocytes as the major source of IL-8 (Yoshimura 1987), recent investigations have identified a variety of cells with the capability to synthesize this polypeptide (Baggiolini 1989). Primary cultures of normal (nontransformed) epithelial cells, fibroblasts, and endothelial cells have been identified as sources of IL8. The production of IL-8 by fibroblasts and epithelial cells is stimulus specific, as IL-1 and TNF, but neither LPS nor interleukin-6 (IL-6), are potent inducing factors for the expression of this chemotactic cytokine (Strieter 1989). As little as $200 \mathrm{pg} / \mathrm{ml}$ of recombinant IL-1 or TNF-alpha could induce the expression of IL-8 mRNA by human fibroblasts in a time dependent fashion, while no constitutive gene expression for this factor was observed. Fibroblast challenged with IL-1 was shown to express steady state IL-8 mRNA by 2 hours and secrete biologically active protein at the 4 hour time point. Interestingly, the expression of IL- 8 mRNA was shown to persist for 48 hours post IL-1 stimulation. The prolonged expression of mRNA for this chemotactic factor was dependent upon continued stimulation, as IL-8 mRNA isolated from fibroblasts challenged with IL-1 and then washed 2 hours later demonstrated a rapid rate of decay.

The above data suggests that cells once thought of as 'bystander cells' can become immune effector cells and actively participate in an inflammatory response. The stimulus specificity factor may prove to be important, as these non-immune cells must rely on an initial host response with the production of appropriate cytokines prior to IL-8 synthesis. This concept is schematically demonstrated in Figure 2. In this diagram the infiltrate of neutrophils into the pulmonary alveoli is regulated by the alveolar macrophage, pulmonary fibroblasts, and type II pneumocytes (lung epithelial cells). Because of their strategic anatomical location, both fibroblast and epithelial cells are in a pivotal position to direct communication circuits during an inflammatory response. This may be especially important in coordinating interactions between the interstitium and the vascular compartment. The production of IL-8 by either IL-1 or TNF triggered accessory cells may explain in part the rapid, specific elicitation of neutrophils associated with a variety of infectious diseases. These 


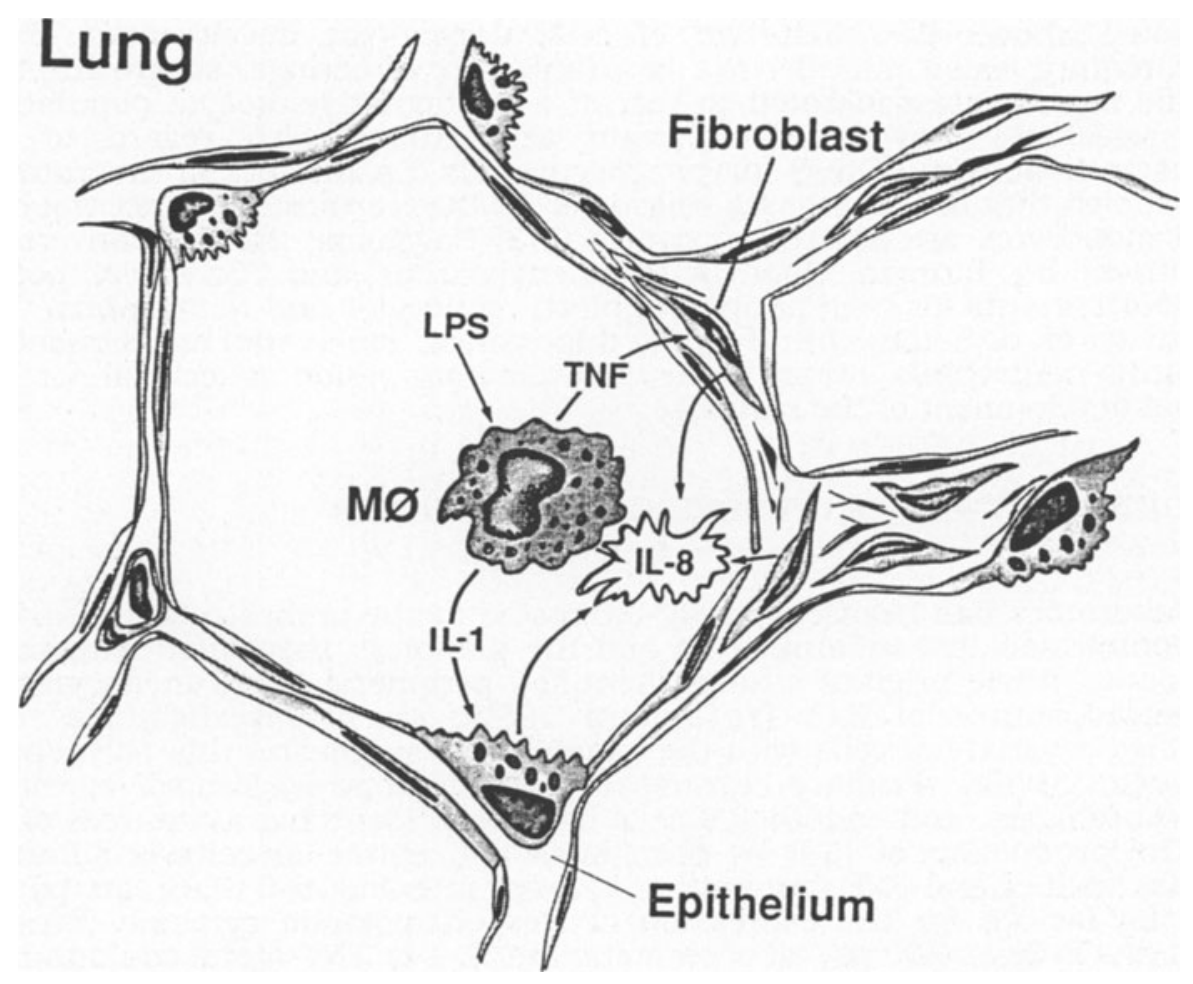

FIGURE 2. Schematic of cytokine networking involving the synthesis of IL-8 by non-immune cells in the lung. In this scenario, alveolar macrophages (MO) can respond to a primary challenge (LPS) and generate IL-8. IL-1 and/or TNF. Other cells that comprise the architecture of the alveolus are not receptive to LPS stipulation, but can synthesize IL-8 in response to the MO-derived IL-1 and TNF. 
observations strengthen the hypothesis that non-immune cells are active in the inflammatory processes and can participate in cell-to-cell communication via cytokine expression.

We have assessed the phenomenon of cytokine networking using conditioned media recovered from either LPS treated human alveolar macrophages or monocytes as a stimulus for lung fibroblast IL-8 gene expression. Since fibroblast do not express IL-8 mRNA in response to LPS, any induction of IL8 would be dependent upon a macrophage-derived cytokine. As shown in Figure 3 , conditioned media generated by the addition of $100 \mathrm{ng} / \mathrm{ml}$ of LPS to human macrophages served as a potent stimulus for steady state mRNA expression by the human fibroblasts. The densitometry of the Northern blots also demonstrate that the conditioned media contained stimulatory levels of IL-1 and TNF, as specific neutralizing antibody to these cytokines were effective in reducing the activity of the conditioned media. Steady state fibroblast IL- 8 mRNA levels could be inhibited by approximately $20 \%$ and 60 $\%$ by the addition of either anti-TNF or anti-IL-1 beta antibody, respectively, to the conditioned media prior to fibroblast stimulation. An important regulatory step in the generation of IL-8 biological activity by fibroblasts appears to involve cytokine networking, as these cells are dependent upon an initial host response prior to IL-8 expression.

Interleukin- 8 has also been shown to play a potentially important role in hepatic cellular communication circuits. Specifically, hepatocytes appear to be an additional source of IL-8 and, as with fibroblasts and epithelial cells, demonstrate stimulus specificity. Lipopolysaccharide was inactive in inducing the expression of IL-8 steady state mRNA and the production of IL8 bioactivity by a variety of human hepatoma lines, while both TNF and IL-1 were potent stimuli. This raises the intriguing possibility that Kupffer cellderived TNF or IL-1 is paramount in the induction of hepatocyte IL-8 synthesis. Indeed, previous studies have demonstrated that LPS is a potent activator for the production of IL-1 and TNF by Kupffer cells (Shirahama 1988). Thus, the generation of hepatocyte-derived IL-8 may be contingent upon the initial production of IL-1 or TNF. One may speculate that this scenario is operative independent of any particular tissue or organ system and this conserved mechanism of cytokine networking is one of the major pathways for the elicitation of granulocytes.

\section{REGULATION OF INTERLEUKIN-8 EXPRESSION}

As described above the production of IL-8 is dependent upon both the cell type and the stimulus under consideration. Interleukin-1, TNF, and LPS appear to be important in activating IL-8 expression by endothelial cells, peripheral blood monocytes, and alveolar macrophages. Other cytokines may play a more subtle role in the production of IL-8. For example, gammainterferon does not have a direct influence on the expression of IL-8 when added alone, but can have a synergistic effect in concert with either LPS, IL1 , or TNF. Since gamma-interferon has previously been shown to stabilize mRNA pools via the regulation of intracellular repressor proteins (Collart 1986), this mechanism may be responsible for the observed synergistic effect. In addition, cyclohexamide can also have a potent synergistic effect on the expression of steady state IL-8 mRNA. LPS, IL-1, or TNF plus 


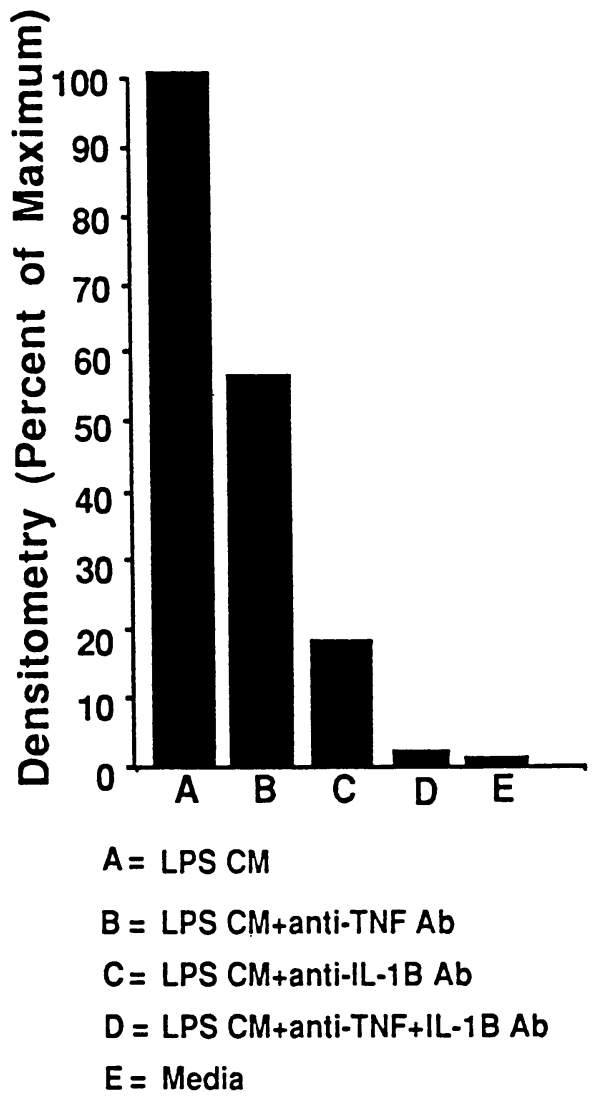

FIGL:RE 3. Densitometry analysis of IL-8 mRNA from Northern blots demcnstrating cytokine networking. Conditioned media from LPS stimulated alveoiar macrophages could induce significant fibroblast IL-8 mRNA. Pretreating the LPS/conditioned media with antibodies directed to either human IL-1 or TNF could dramatically decrease the expression of IL-8 mRNA. 
cyclohexamide can serve as primary inducing signals for IL-8 mRNA expression, demonstrating that de novo protein synthesis is not needed for transcription of this chemotactic cytokine. In the presence of cyclohexamide either of the above three stimuli can superinduce transcription of IL-8; further supporting the concept that IL- 8 is under the control of intracellular repressor proteins.

Although specific cytokines have been identified that can induce the expression of IL-8 by a variety of cells, the regulatory mechanisms that control the expression of this chemotactic cytokine have not been fully explored. Initial studies have demonstrated IL-8 production by monocytes, fibroblasts, and synovial cells was down-regulated by dexamethasone (Mukaida 1989, Watson 1988). While this anti-inflammatory steroid can modulate the expression of IL- 8 by these cells, the dexamethasone effect is not universal in all cells. For example, the production of IL- 8 by endothelial cells is not susceptible to dexamethasone-induced regulation. Although the production of a number of cytokines appear to be negatively influenced by agents that increase intracellular CAMP, IL-8 mRNA production was not reduced when cells were co-challenged with either prostaglandin $\mathrm{E}$ or dibutyryl CAMP and IL-1 or TNF. In fact, an elevation in CAMP appeared to slightly enhance steady state IL-8 mRNA in a variety of cell systems (unpublished observations). Recent investigations in our laboratory have identified a polypeptide with potent suppressive activity for monocyte-derived IL-8. The cytokine interleukin-4 (IL-4), over a wide dose response range, can dramatically reduce LPS-stimulated monocyte steady state IL- 8 mRNA levels. Concentrations of $\mathrm{IL}-4$ in the $\mathrm{pg} / \mathrm{ml}$ range were effective in regulating the expression of IL-8. Furthermore, the regulatory influence of IL-4 was not only effective on LPS treated monocytes, but also on IL-1 and TNF treated monocytes. The suppressive effect of IL- 4 on IL-8 transcription was reflected in a reduction of antigenic and biologically active protein. The above data is in line with other reports demonstrating that IL-4 may be a powerful regulatory cytokine for monocyte activity (Hart 1989).

The modulation of IL- 8 gene expression by IL- 4 has a number of important in vivo implications. As stated above, one of the unique aspects of an evolving immune response is the characteristic "waves" of inflammatory cells that are recruited to an evolving lesion. Most developing inflammatory lesions have an initial neutrophil component and, if the response becomes chronic, a mononuclear infiltrate will usually follow. The recruitment 'switch' from neutrophils to mononuclear cells is not well understood and has been an enigma of the immune response. New insight into this unknown may be on the horizon with the discovery of specific classes of chemotactic cytokines and agents that control their synthesis. One scenario that may be important in the regulation of IL-8 expression and thus fine tuning the cellular infiltrates is shown in Figure 4. In this diagram the termination of neutrophil recruitment is shown to be under the regulatory influence of the next wave of immune cells, the lymphocytes. Since redundancy exists in the recruitment system, the mononuclear cells are presumably being elicited initially by alternate mechanisms. 


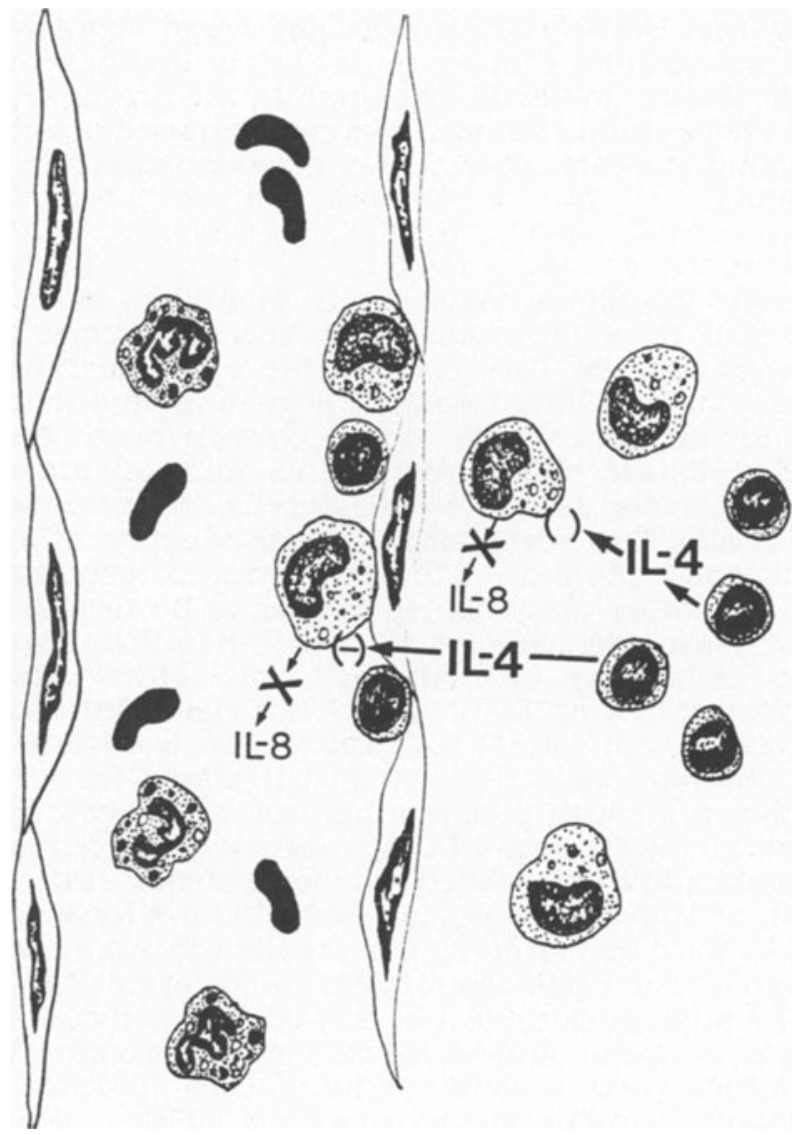

FIGURE 4. Regulatory cytokine circuits that may be operative in suppressing IL-8 expression as a lesion becomes chronically inflamed. As specific lymphocyte populations begin to accumulate at an inflammatory site, they can produce IL-4 which is a potent regulatory cytokine for monocyte IL-8 production. This paracrine activity may aid in explaining the absence of neutrophils in lesion that are predominantly mononuclear in nature. 


\section{CLINICAL IMPORTANCE OF IL-8 AND TNF IN REPERFUSION INJURY}

Although certain cytokines do appear to be involved in the pathologic alternations of sepsis, this disease state is not the only clinically important process in which cytokines such as TNF have a leading role. Elevated levels of TNF appear to be involved in the inflammatory processes associated with other specific disease states. Recent studies from our laboratory have demonstrated that this interesting cytokine is involved in the adverse changes that occur during ischemia/reperfusion. Using an established model of lobar ischemia/reperfusion, rather than total hepatic ischemia, an ischemic insult to the liver was induced without inducing mesenteric venous hypertension. A microaneurysm clip was used in these studies to stop both portal venous and hepatic arterial blood flow to the 3 cephalad lobes of the liver, while the 3 caudal lobes retained normal portal and venous flow. This aspect of the rat model is important, as intestinal venous congestion was prevented which negated bacterial translocation from a potentially ischemic small bowel. The levels of bioactive TNF found in the sera correlated with the length of ischemia. In these studies a catheter was positioned in the supra-hepatic vena cava in order to obtain immediate post-hepatic blood samples. Ninety minutes of ischemia proved to be of significant time to induce the synthesis of TNF. In a subsequent kinetic analyses, TNF was monitored in the sera at specific time intervals post reperfusion. The peak in TNF levels were found to be variable as they reached a zenith by 3 hours post reperfusion. The peak concentration of TNF ranged between 9-141 $\mathrm{pg} / \mathrm{ml}$ of rat serum. Pathology induced by the hepatic ischemia/reperfusion was identified as a neutrophilic sequestration with edematous changes in the lungs. The accumulation of neutrophils may be due to the induction of IL- 8 by cells stimulated with TNF, as it is now known that TNF can increase the expression of IL-8 in a network fashion. The histologic alterations in the lungs may not be too surprising considering that the next vascular bed past the liver is in the lung. Therefore, this organ is in a location to fully receive the impact of mediators released down stream. This observation was of great interest, since the pulmonary injury post hepatic ischemia/reperfusion mimicked the pattern of injury following direct intravenous administration of recombinant TNF to rats. Interestingly, pretreatment of rats prior to ischemia/reperfusion with neutralizing antibodies dramatically reduced the pulmonary injury pattern. The anti-TNF antibody therapy reduced the lung permeability changes from a mean permeability index of 0.6 to $0.2(p<0.05)$ using preimmune sera as compared to anti-TNF sera, respectively. In addition to salvaging the lung, the antibody treatment significantly decreased the pathology of the liver itself. This was identified as a maintenance of hepatocyte integrity and a reduction of neutrophilic infiltrates.

\section{CONCLUDING REMARKS}

The recruitment of granulocytes from the circulation, through the endothelium and basement membrane, and into the interstitium of inflamed tissue is of important immunopathologic consequence. This cascade of events is likely mediated to a large extent by the chemotactic cytokine, IL-8. A number of diseases and disorders are characterized by a significant elicitation of neutrophils, including late phase asthma, idiopathic pulmonary fibrosis, asbestosis, multiple organ failure, immune complex vasculitis, 
inflammatory bowel disease, psoriasis, and ischemia/reperfusion injury. Although the organ or tissue associated with these diseases are quite diverse, the histopathology of these reactions with largely neutrophilic infiltrates are strikingly similar. Thus, the fundamental mechanism(s) that are responsible for the recruitment of granulocytes appear to be common to all tissue. Of particular interest, is the infiltrate associated with ischemia/ reperfusion injury and the potential role of IL-8 in mediating this response. Four to eight hours post reperfusion of ischemic tissue a classic neutrophil infiltrate can be observed; yet, the recruitment mechanism is unknown. Interleukin-8 synthesis by endothelial cells and fibroblasts in the ischemic area at risk may be a leading candidate for the initiation of leukocyte recruitment. The concept that non-immune cells can possess 'effector cell' activity and actively participate in an inflammatory response via the synthesis of IL-8 is noteworthy.

The ubiquitous expression of IL- 8 in response to IL- 1 and TNF raises a number of important questions with regard to alternate activities of this chemotactic cytokine. Recent studies by Gimbrone et al (Gimbrone 1989) have identified a endothelial cell-derived IL-8 as a leukocyte adhesion inhibitor. In these provocative investigations, IL-8 appears to attenuate the inflammatory response by altering the adhesion of neutrophils to IL-1 activated endothelium. Other investigators have made a strong case for the role of IL-8 as an immuno-enhancer, since the systemic in vivo administration of IL-8 causes a profound neutrophilia (Van Damme 1988, Colditz 1989). Data from the latter study indicates that IL-8 may have therapeutic activity in immunosuppressed patients. In addition, both the wide spread production and relatively high concentration of IL-8 secreted by stimulated non-immune cells suggests other roles for this cytokine. The production of IL-8 by fibroblasts raises the speculation that collagen deposition and the fibrotic response may be under the influence of this factor. The close structural relationship with growth related gene products may imply that IL-8 is involved in cell proliferation or associated with a specific aspect of the cell cycle. Further investigations are needed to fully understand the impact of this important cytokine in normal and pathophysiologic functions.

ACKNOWLEDGEMENTS The authors wish to thank the expert secretarial support of Suzanne Miller and Peggy Weber. This work was supported in part to NIH grants HL31693, HL35276, and DK38149. Steven L. Kunkel is an established investigator of the American Heart Association. 


\section{REFERENCES}

Anisowicz, A, Bardwell, L, and Sager, R (1987) Constitutive overexpression of a growth-regulated gene in transformed Chinese hamster and human cells. Proc Natl Acad Sci USA 84: 7188-7192.

Baggiolini, M, Walz, A, and Kunkel, SL (1989) NAP-1/IL-8, a novel cytokine that activates neutrophils $\mathrm{J}$ Clin Invest $84 ; 1045-1049$.

Begg, GS, Pepper, DS, Chesterman, CN, and Morgan, FJ Complete covalent structure of human beta-thromboglobulin. (1978) Biochemistry 17, 17391744.

Castor, CW, Miller, JW, and Walz, DA (1983) Structural and biological characteristics of connective tissue activating peptide CTAP-III), A major human platelet-derived growth factor. Proc Natl Acad Sci USA 80, 765769.

Colditz, I, Zwahlen, R, Dewald, B and Baggiolini, M (1989) In vivo inflammatory activity of neutrophil activating factor, a novel chemotactic peptide derived from human monocytes. Amer J Pathol 134;755-760.

Collart, MA, Belin, D, Vassalli, J, DeKossodo, S, and Vassalli, D. (1986) Gamma interferon enhances macrophages transcription of the tumor necrosis factor/cachectin, interleukin-1, and urokinase genes, which are controlled by short-lived repressors. J Exp Med 164, $2113-2121$.

Deuel, TF, Keim, PS, Farmer, M, and Heinrikson, RL (1977) Amino acid sequences by human platelet factor 4 . Proc Natl Acad Sci USA 74, 22562258.

Devatelis, G, Tekamp-Olson, P, Wolpe, SD, Hermsen, K, Luedke, C, Gallegos, C. Coit, D, Merryweather, J, and Cerami, A (1988) Cloning and characterization of a cDNA for murine macrophages inflammatory protein (MIP), a novel monokine with inflammatory and chemokinetic properties. J Exp Med 167, 1939-1944.

Fernandez, HN, Henson, PM, Otani, A, and Hugli, TE (1978) Chemotactic response to human $\mathrm{C} 3 \mathrm{a}$ and $\mathrm{C} 5 \mathrm{a}$ anaphylatoxin. J Immunol 120, 109121 .

Furutani, Y, Nomura, H, Notake, M, Oyamada, Y, Fukui, T, Yamada, M, Larsen, CG, Oppenheim, JJ, and Matsushima, K (1989) Cloning and sequencing of the cDNA for human monocyte chemotactic and activating factor (MCAF). Biochem. Biophys Res Comm 159, 249-255.

Gimbrone, MA, Obin, MS, Brock, AF, Luis, EA, Hass, PE, Hebert, CA, Yip, YK, Leung, DW, Lowe, DG., Kohr, WJ, Darbonne, WC, Bechtol, KB, and Baker, JB (1989) Endothelial interleukin-8: a novel inhibitor of leukocyteendothelial interactions. Science, 246, 1601-1603.

Hart, P H, Vitti, GF, Burgess, DR, Whitty, GA, Piccoli, DS.., and Hamilton, JA (1989) Potential anti-inflammatory effects of interleukin-4: suppression of human monocyte tumor necrosis factor- $\alpha$, interleukin-1 and prostaglandin $\mathrm{E}_{2}$. Proc Natl Acad Sci USA 86, 3803-3807.

Hoover, RL, Karnovsky, MJ, Austen, KF, Corey, EJ, and Lewis, RA (1984) Leukotriene $\mathrm{B}_{4}$ : an inflammatory mediator in vivo. Proc Natl Acad Sci USA 81, 2191-2193.

Issekutz, A, Megyeri, P, and Issekutz, TB (1987) Interleukin-1: an endogenous mediator of inflammation and the local Schwartzmann reaction. Lab Invest 56, 49-59.

Issekutz, A, and Bhimji, S (1982) Role for endotoxin in the leukocyte infiltration accompanying $\mathrm{E}$. coli inflammation. Infect Immun 36, 588597. 
Lindley, I, Aschauer, H, Seifert, J, Lam, C, Brunowsky, W, Kownatzki, E, Thelen, M. Oeveri. P, Dewald, B, Von Tscharner, V, Walz, A, and Baggiolini, M (1988) Synthesis and expression in E. coli of the gene encoding monocyte-derived neutrophil activating factor: biological equivalence between natural and recombinant neutrophil activating factor. Proc Natl Acad Sci USA 85, 9199-9203.

Luster, TA. Unkeless, JC, and Ravetch JV (1985) Gamma interferon transcription regulates an early response gene containing homology to platelet proteins. Nature 315,672-676.

Matsushima, K, Morishita, K, Yoshimura, T, Lavu, S, Kobayashi, Y, Lew, W, Apella, E, Kung, HF, Leonard, EJ, and Oppenheim, JJ (1988) Molecular cloning of a human monocyte-derived neutrophil chemotactic factor (MDNCF) and the induction of MDNCF mRNA by interleukin-1 and tumor necrosis factor. J Exp Med 167;1883-1893.

Mukaida, N, Shiroo, M, and Matsushima, K (1989) Genomic structure of the human monocyte-derived neutrophil chemotactic factor IL-8. J Immunol 143,1366-1371.

Richmond, A, Balentien, E, Thomas, HG, Flaggs, DG Bartin, DE, Spiess, J, Bordoni, R, Francke, U, and Derynck, R (1988) Molecular characterization and chromosomal mapping of melanoma growth and stimulatory activity, a growth factor structurally related to beta-thromboglobulin. Embo J 7, 2025-2034.

Rollins, BJ, Morrison, ED, and Stiles, CD (1988) Cloning and expression of $\mathrm{JE}$, a gene inducible by platelet derived growth factor and whose product has cytokine-like properties. Proc Natl. Acad Sci USA 85, 3738-3742.

Sauder, DN, Mounessa, NL, Katy, CA, Dinarello, CA, and Gallin, JI (1984) Chemotactic cytokines: The role of leukocyte pyrogen and epidermal cell thymocyte-activating factor in neutrophil chemotaxis. J Immunol 132 , 828-839.

Schiffmann, E, Corcoran, BA, and Wahl, SM (1975) N-formylmethionyl peptides as chemoattractants for leukocytes. Proc Natl Acad Sci USA 72, 1059-1070.

Schmid, J and Weissmann, C (1987) Induction of mRNA for a serine protease and a beta thromboglobulin-like protein in mitogen-stimulated human leukocytes. J Immunol 139,250-256.

Shirahama, M, Ishibashi, H, Tsuchiya, Y, Kurokawa, S, Okumura, Y, and Nino, $Y$ (1988) Kinetics and parameters of the induction of interleukin-1 secretion by rat Kupffer cells. J Clin Lab Immunol 27, 127-134.

Springer, TA, Dustin, ML, Kishimoto, TK and Marlin, SD (1987) The lymphocyte function-associated LFA-1, CD2, and LFA3 molecules: cell adhesions receptor of the immune system. Annu Rev Immunol 5, 223252.

Strieter, RM, Phan, SH, Showell, HJ, Remick, DG, Lynch, JP, Genord, M, Raiford, C, Eskandari, M, Marks, RM and Kunkel, SL (1989) Monokineinduced neutrophil chemotactic factor gene expression in human fibroblasts. J. Biol. Chem. 264, 10621-10626.

Strieter, RM, Kunkel, SL, Showell, HJ, Remick, DG, Phan, SH, Ward, PA, and Marks, RM (1989) Endothelial cell gene expression of a neutrophil chemotactic factor by TNF- $\alpha$, LPS, an IL-1 $\beta$. Science $243,1467-1469$.

Sugano, S, Stoeckle, MY, and Hanafusa, $\mathrm{H}$ (1987) Transformation by rous sarcoma virus induces a novel gene with homology to a mitogenic platelet protein. Cell 49, 321-328. 
Thelen, M, Peveri, P, Kernen, P, Von Tscharner, V, Walz, A, and Baggiolini, M (1988) Mechanism of neutrophil activation by NAF, a novel monocytederived peptide agonist. FASEB J. 2, 2702-2706.

Van Damme, J, Van Beeumen, J, Conings, R, Decock, B, and Billiau, A (1989) Purification of granulocyte chemotactic peptide/interleukin-8 reveals $\mathrm{N}$-terminal sequence heterogeneity similar to that of thromboglobulin. Eur. J. Biochem. 181, 337-344.

Van Damme, J, Van Beeumen, J, Opdenakker, G, and Billiau, A (1988) A novel, $\mathrm{NH}_{2}$-terminal sequence characterized human monokine possessing neutrophil chemotactic, skin-reactive, and granulocytosis promoting activity. J Exp Med 167, 1364-1376.

Watson, ML, Westwick, J, Fincham, NJ and Camp, RDR (1988) Elevation of PMN cytosolic free calcium and locomotion stimulated by novel peptides from IL-1 treated human synovial cell cultures. Biochem Biophys Res Comm 155, 1154-1160.

Westwick, J, Li, SW, and Camp, RD (1989) Novel neutrophil stimulated peptides. Immunol Today 10, 146-148.

Yoshimura, T, Yuhki, N.., Moore, SK, Appella, E, Lerman, MI, and Leonard, EJ (1989) Human monocyte chemoattractant protein-1 (MCP-1). FEBS Letters 244, 487-493.

Yoshimura, T, Matsushima, K, Tanaka, S, Robinson, EA, Appella, E, Oppenheim, JJ, Leonard, EJ (1987) Purification of a human monocytederived neutrophil chemotactic factor that shares sequence homology with other host defense cytokines. Proc Natl Acad Sci USA 84, 9233-9237. 
Malik:

If you are showing that IL-8 can be synthesized by various cells in the lung, i.e. the macrophage monocytes as well as various interstitial cells, such as the fibroblast, and perhaps even the epithelium, then how could it serve as a chemotactic agent? How would the concentration gradient to drive the neutrophils from the vascular space to the interstitial space be generated?

\section{Kunke l:}

One aspect I did not have time to talk about was the regulation of IL-8. And what appears is that these cells are differently regulated with regard to what is turning them on, what is turning them off. And so what happens is that the mononuclear phagocytic cells end up being fairly susceptible to regulation, the fibroblasts end up being fairly susceptible to some sort of regulation, so I think what there is is not only a cascade affecting the positive signals, but also some sort of cascade affecting the negative signals that are sequentially turning these factors on and off. In a normal case, I think it is finetuned and it runs well. In a case where you have the go signal to get around with this TNF or LPS, I think the go signal is always on and the negative off signals never have a chance to get upregulated.

\section{Malik:}

There may be another way of coming to terms with this idea. ICAM upregulation may be important in the neutrophil migration process; in other words, there may be regional domains of the endothelium near the interendothelial junctions where ICAM may be upregulated. Therefore, it is possible that neutrophils can attach to these upregulated ICAM molecules, and this may be how migration proceeds. Can IL-8 serve as an upregulator of ICAM activity?

\section{Kunke l:}

There have been some reports suggesting that this occurs, although the data are not clear. The data that we have generated look as if granulocytes or monocytes bind to the endothelium (or if you come in and occupy the LFA receptor with an antibody); that in itself will serve as an initiating trigger for the expression of the chemotactic factor. So it makes sense to us that the binding of a monocyte to the endothelium is probably one of the first initiating factors that starts upregulating the expression of certain cytokines. So not only does it stick to the endothelium, it also starts expressing factors as need to participate inflammatory response, including the chemotactic factors.

\footnotetext{
Sturm:

We could not measure TNF or interleuk in, but your ideas about pathogenes is $f$ it exactly to our clinical findings and to our ideas about pathogenes is of this disease. First, in bronchoalveolar lavage we found PMNs outside in the alveoli completely emptied, exhausted and a lot of free elastase in the alveoli. Second, it is believed by another group working with us that surfactant fragments are the chemotactic stimuli for the permeation of the PMNs. And third, another one of your observations fits also very well to our measurements. We could prove permeability damage of the alveoli and the endothelium early after trauma. Later on we found a nonexplainable retightening of the alveoli wal1, about the 6 th, 7 th, 8 th day it becomes tight again. And this could be a result of the fibroblast activity you reported. We have seen this process also by electron microscopy and we could measure albumin gradients. All of a sudden we did not see any more permeability damage of the endothelium. We did not understand it. This would fit exactly into your idea about activated fibroblasts.
} 
Wells:

That was an elegant presentation, Steve. I have a question because I am egocentric, and I am always trying to figure out how this applies to the intestinal tract. Considering those experiments involving IL-8 and macrophages that were cultured either at room air or under extremely aerobic conditions, I was wondering, I cannot imagine areas such as the intestinal tract or other intraperitoneal wounds, for example, ever being aerobic or even at room air. What would happen if you incubated or repeated the same experiment under anaerobic conditions?

Kunke l:

Yes, we have done that and we do not see the same potentiation. We just started those studies and it looks like anaerobic condition by itself may initate the production of IL-8, although it is nothing like the levels we see in hyperoxia conditions. You can talk to the critical care people here, and they routinely use 95\% oxygen when people are critically $i 11$.

Wells:

I have learned a little bit lately about hyperbaric oxygen. One of the reasons hyperbaric oxygen maybe good in some instances and not in others is that while hyperbaric oxygen may be toxic to anaerobic bacteria, the tissue macrophage needs an anerobic environment in which to exert its bactericidal effect.

\section{Kunke l:}

Well, it is a trade-off because if the pulmonologists do not use high oxygen the people will die. They have to treat patients in this manner to make sure that they get oxygenation. People are probably better able to cope with anoxia conditions than hyperoxia. When you exercise your muscles they are anoxic for a long time, you get lactic acid built up, and you are stiff for a day or two, but after that you are fine. But it looks like if you expose cells to hyperoxia for a long time, you end up with cell death. It is not good for you. So that is why for people who are intubated, you have to be very careful in monitoring them. People who get treated for lung cancers receive radiation and can get lung damage; in this damage you get a tremendous elicitation of neutrophils. There is no infection, but you get elicitation neutrophils. People who are on bleomycin, an anticancer therapy, also receive an oxygen-radical-induced injury that can result in elicitation of neutrophils into the lungs. So there are a lot of other instances of disease states and treatments which lead to neutrophil infiltrates, which are not associated with bacterial infection.

Red 1:

You showed this ischemia-reperfusion-related TNF production. Do you have a mechanism or do you believe what, for instance, Dr. Wendel from Konstanz believes, that it is an oxygen-radical-related action, acting on antiproteases, inactivating them, and in this way, then the proteases are able to liberate TNF, which would otherwise be bound to the cells? The second question is, if you could clarify for us these recent reports by Gimbrone's group that the IL-8, which comes from endothelial cells, actually inhibits adherence of neutrophils to the endothelium?

\section{Kunke l:}

Let me answer the last question first, because it is easier: Gimbrone has been working with essentially different peptides. He has been working with a 77 amino acid protein which has five extra amino acids. That may not exist in a normal in vivo situation because that protein is extremely susceptible to proteolytic digestion to a 72 amino acid protein, the latter IL-8 that most people work with, which is very stable. The way that Gimbrone's lab has been approaching the antiinf lammatory effects of IL-8 is to treat animals with very large levels of IL-8 and then give them intradermal injection of $\mathrm{IL}-8$ and look for infiltrates. You can set up the same experiment with $C 5 \mathrm{~A}$ and not have neutrophil infiltrates. I think that maybe it is worth looking at fully, but I think it is a puzzle right now. I think the whole story is not in. 
Now, with regard to the preformed TNF, we have never been able to find preformed TNF in monocytes.

Redl:

No, I do not mean preformed but synthesized membrane- bound TNF is then only released because of oxygen radical mechanisms.

Kunke l:

I really have no data to refute this hypothesis.

Redl:

So you have currently no explanation why you get this TNF response in the ischemia-reperfusion situation?

Kunke l:

Well, I think we are getting upregulation from probably the Kupffer cells themselves; this cell is a respectable source of TNF.

Deitch:

I have two questions for you. The first one is why does the nonischemic lobe of the liver not get a late injury since this tissue is ultimately exposed to circulating factors released by the injured liver? The second question is have you done any studies to show that IL-8 is causally important? It seems that there are a number of other potential mediators that are liberated at the same time that in the absence of IL-8 may cause leukosequestration and neutrophil-mediated injury. So the question is: What is the role of IL-8? One concern is the fact that most people have not consistently been able to find TNF in many of the syndromes in which we would expect the tissue injury to be mediated by TNF. Your data show a small peak in TNF; so that would lead me to believe that IL-8 may be the effector molecule, and if so, have you carried out any IL-8-blocking studies?

Kunke 1:

First of all, let me address the neutropenic issue. If you look at the numbers of patients who are neutropenic who get ARDS, the numbers are incredibly small, absolutely small. The observation I think everyone else would agree with is that shock and shock-like syndromes in seps is are an extremely complicated thing. With regard to the role of IL-8, I think that it is important not only in ARDS but in many diseases. I think that IL-8 is a protein molecule which is instrumentally important in normal recruitment of inflammatory cells during inflammation. I think it is one of the major mechanisms that is involved in recruiting cells other than the complement cascade. The reason why we became interested, if you go back and read the chemotactic factor literature associated with ARDS and recruitment of neutrophils, is that scientists have published long articles telling you what the chemoattractants are not, but they do not know what they are. And I do not know if IL-8 is going to be involved in ARDS. I just came from the American Thoracic Society Meet ing in Boston last week and there were three abstracts there showing you can identify antigenic IL-8 in lavage fluid of patients with ARDS. The problem is there is no rodent equivalent of IL-8 yet, so models are hard to address. 